\title{
Distribution of peak expiratory flow variability by age, gender and smoking habits in a random population sample aged 20-70 yrs
}

\author{
H.M. Boezen*, J.P. Schouten*, D.S. Postma**, B. Rijcken*
}

\begin{abstract}
Distribution of peak expiratory flow variability by age, gender and smoking habits in a random population sample aged 20-70 yrs. H.M. Boezen, J.P. Schouten, D.S. Postma, B. Rijcken. CERS Journals Ltd 1994.

ABSTRACT: Peak expiratory flow (PEF) variability can be considered as an index of bronchial lability. Population studies on PEF variability are few. The purpose of the current paper is to describe the distribution of PEF variability in a random population sample of adults with a wide age range (20-70 yrs), and to assess relationships to age, gender and smoking habits.

PEF data were collected in 511 participants of the Dutch part of the European Community Respiratory Health Survey.

A training effect was found, absolute PEF values on the first measurement day being significantly lower. Females had greater PEF variability (adjusted for age, height and pack-years) and lower absolute PEFs than males. The mean within-day variation (amplitude \% mean) was 3.66\% (SD 2.03\%), whereas the mean day-today variation was relatively small: $0.08 \%$ (SD 1.53\%). Absolute PEFs were lower and amplitude \% mean were significantly higher in older age groups. Smoking was significantly associated with lower mean PEFs and greater amplitude \% mean. We observed lower mean values of the amplitude \% mean than other investigators, possibly related to lower frequency of PEF recording (twice daily).

We conclude that PEF and PEF variability have a normal or log-normal distribution. When studying PEF variability, age, gender and smoking habits should be taken into account.
\end{abstract}

Eur Respir J., 1994, 7, 1814-1820.

Depts *Epidemiology and Statistics, and **Pulmonology, University Hospital Groningen, The Netherlands.

Correspondence: B. Rijcken

Dept of Epidemiology and Statistics

University of Groningen

Ant. Deusinglaan 1

9713 AV The Netherlands

\author{
Keywords: Age \\ gender \\ peak expiratory flow variability \\ smoking
}

Received: March 221994

Accepted after revision July 61994

This study was supported by a grant from The Ministry of Wellbeing, Public Health and Culture, The Netherlands, Jan Kornelis de Cock Foundation, Groningen, The Netherlands, and The Netherlands Asthma Fund, Grant No. 92.12.
Bronchial responsiveness to histamine or methacholine assessed in challenge testing is considered an objective measure for bronchial lability [1]. Bronchial responsiveness is related to the presence of respiratory symptoms [2-4], asthma [5], and the severity of asthma [1]. It is also frequently expressed in established chronic obstructive pulmonary disease (COPD) [6], and is an important risk factor for the development of airway obstruction [7]. Measuring peak expiratory flow (PEF) variability has often been promoted as a good alternative for challenge testing [8]. Associations between PEF variability and bronchial responsiveness have been observed both in asthmatic and COPD patients [9-12], although the two phenomena are not interchangeable [9].

PEF variability can be assessed both as the variation in PEF within a day, and the variation in PEF over several days [13]. The PEF has a $24 \mathrm{~h}$ rhythm, minimum PEF values generally, but not always, being observed at night or early morning, and maximum values at the end of the afternoon [14-16]. The difference between the minimum and maximum PEF is known to be greater in (untreated) asthmatics than in normals [6]. Twice daily PEF measurements are regularly used in general and clinical practice to monitor asthmatic patients, and PEF meters are considered useful devices to screen for asthma in a random population. Two epidemiological studies have shown PEF variability to be larger when hyperresponsiveness is present $[3,17]$.

There are several advantages of measuring PEF variability over challenge testing. PEF variability is easily and safely assessed, with simple and cheap equipment. Subjects can perform reliable measurements after instruction at the work place or at home, whereas responsiveness testing can only take place in laboratory settings. Moreover, PEF variability can be assessed in all subjects, including those who would not have been allowed to perform a challenge test because of low pulmonary function, respiratory symptoms, cardiovascular disease or drug therapy. Studies on PEF variability in patients [9] and in occupational populations [17], and in their families [8], have given information on the feasibility and reliability of measuring peak flow at home and at work in these selected groups.

So far, only Higgins et al. [18] have investigated variability of PEF in a random sample of the general population. The purpose of the current paper is to describe 
the distribution of PEF variability in a random population sample of adults with a wide age range (20-70 yrs), and to assess relationships to age, gender and smoking habits.

\section{Material and methods}

Data on PEF variability were collected in participants of the Dutch part of the European Community (EC) Respiratory Health Survey, a European multicentre study on respiratory health. In the city of Groningen, The Netherlands, 1,500 subjects aged 20-70 yrs, were randomly sampled from the local administration registry. This registry represents the complete population of the communicipality, and provides a perfect and complete sample scheme. The subjects were sampled by 10 yr age groups and gender to achieve adequate numbers for each gender-age group. All subjects visited the Community Health Centre for screening purposes. Data on smoking habits were collected by means of the standardized questionnaire of the EC Respiratory Health Survey. Smoking habits were expressed both as a categorical and a continuous variable. Subjects were defined as "current smokers" if they smoked at least one cigarette $\cdot$ day $^{-1}$ during the last year. "Ex-smokers" were those subjects who had stopped smoking at least one month previous to the examination. "Never-smokers" were those subjects who had never smoked. The cumulative amount of cigarettes ever smoked was calculated and expressed in pack-years ( 1 pack-year $=25$ cigarettes $\cdot$ day ${ }^{-1}$ during one year).

Participants received a mini-Wright PEF meter (Clement Clarke International Ltd, London, UK) and were instructed by a trained technician who demonstrated the correct use of the meter and the recording form. After instruction, participants had to be able to perform the peak flow test correctly. They received an instruction folder showing photos and the following written instructions: 1) perform the test standing (preferably, or at least in the same position each time); 2) hold the meter lightly and do not interfere with the movement of the marker (arrow) or cover the slot; 3 ) do not grip the meter too tightly; 4) take a deep breath and place the mouthpiece end into your mouth and make an airtight seal with your lips around the mouthpiece; 5) blow into the mini-Wright as hard and as fast as you can; 6) read the value at the pointer and write this down on the PEF recording form; 7) return the pointer to its "zero" position; 8) repeat the test twice more so that you end up with a series of three readings [8, 19].

Participants had to perform PEF measurements at home every morning on rising, and again every afternoon between 5-6 p.m., before dinner, for seven successive days. The highest values of the morning and the afternoon were used in the analyses. If subjects were taking bronchodilator therapy, PEF values had to be measured before its use. Functioning of every single peak flow meter was checked by a trained technician before distribution and upon return. Each participant's mean morning PEF and mean afternoon PEF was calculated, over a period of at least 5 days.
PEF variability was assessed in two ways: 1) withinday variation, amplitude \% mean, defined as (highest $\mathrm{PEF}-$ lowest $\mathrm{PEF}) /($ mean value of the two $) \times 100 \%$, averaged over at least five days [14]; and 2) day-to-day variation of morning PEF - (highest morning PEF - highest morning PEF of the day before/(mean value of the two) $\times 100 \%$, averaged over at least five days [9].

Distributions of PEF values were inspected visually by frequency histograms of the total population and for males and females separately. The Kolmogorov-Smirnov test (KS-test) was used to formally test distributions for normality. In case of normal distribution, parametric tests were used (Student's t-test, analysis of covariance (ANCOVA) by multiple regression method). The association of age with PEF variability was analysed by linear regression for males and females separately, with adjustment for height and smoking habit, with age and height centred to the mean values of, respectively, males and females (mean centred age (m.c. age) and mean centred height (m.c. height)). This results in informative intercepts (constants) in linear regression equations. With skewed distributions, log transformations were performed to normalize the distributions. If normalization was not possible, nonparametric analyses were performed (Mann-Whitney U-test, Kruskall-Wallis ANOVA, $\chi^{2}$-test or Spearman's r). All tests were performed two-sided, unless otherwise mentioned. Values of $p<0.05$ were considered significant. All analyses were performed with the SPSS/PC+-V4.0 package. Results are presented as means (SD), unless stated otherwise.

\section{Results}

\section{Population characteristics and PEF data}

In the city of Groningen, 1,500 subjects were invited for an extensive respiratory health test at the Community Health Centre, and 836 subjects responded to this invitation $(57 \%)$. These 836 subjects were compared to the nonresponders, using data from a previously administered mailed questionnaire. Responders were more likely to be older and to have symptoms, but these differences were small and not significant. Of these responders, 579 were randomly asked to join the PEF variability study and $573(99 \%)$ of them agreed to participate. A completed and readable PEF recording form was received from 520 subjects $(91 \%)$. The excluded group did not differ from the analysed group in age and sex distributions, but contained relatively more current smokers and less lifetime nonsmokers $\left(\chi^{2}\right.$-test, $\mathrm{p}<0.001)$.

The mean morning PEF of the study population on the first day $\left(509 l \cdot \mathrm{min}^{-1}\right)$ was significantly $(\mathrm{p}<0.05)$ lower than the mean morning PEF of days 2, 3, 4, 5, 6 and 7 $\left(513,512,513,513,512,515 l \cdot \mathrm{min}^{-1}\right.$, respectively) (fig. $1)$. The same pattern occurred in the mean afternoon PEF (523 l. $\mathrm{min}^{-1}$; respectively, 528, 525, 525, 524, 525, $\left.526 l \cdot \mathrm{min}^{-1}\right)(\mathrm{p}<0.05)$ (fig. 1). This pattern confirms the 
Table 1. - Age, pack-years and values of morning PEF, afternoon PEF, amplitude \% mean and day-to-day variation by gender and smoking habit

\begin{tabular}{|c|c|c|c|c|c|c|}
\hline \multirow[t]{2}{*}{ Variable } & \multicolumn{3}{|c|}{ Males $(n=265)^{+}$} & \multicolumn{3}{|c|}{ Females $(n=246)$} \\
\hline & $\begin{array}{c}\text { Lifelong } \\
\text { nonsmoker }\end{array}$ & Ex-smoker & $\begin{array}{l}\text { Current } \\
\text { smoker }\end{array}$ & $\begin{array}{c}\text { Lifelong } \\
\text { nonsmoker }\end{array}$ & Ex-smoker & $\begin{array}{l}\text { Current } \\
\text { smoker }\end{array}$ \\
\hline $\mathrm{n}, \%$ & $69,26 \%$ & $90,34 \%$ & $103,39 \%$ & $120,49 \%$ & $60,24 \%$ & $66,27 \%$ \\
\hline Age yrs & $39 \quad(14)^{*}$ & $55 \quad(12)$ & $46 \quad(13)$ & $45 \quad(16)^{* *}$ & $47 \quad(12)$ & $41 \quad$ (13) \\
\hline Height $\mathrm{m}$ & $1.82(0.08)$ & $1.78(0.06)$ & $1.78(0.07)$ & $1.67(0.06)$ & $1.66(0.06)$ & $1.66(0.06)$ \\
\hline Pack-years & - & $17.3(16.3)$ & $23.4(15.3)$ & - & $13.3(15.5)$ & 17.8 \\
\hline Morning PEF $l \cdot \mathrm{min}^{-1}$ & $620(78)^{*}$ & $580(94)$ & 557 (101) & $443(74)^{*}$ & 432 (84) & $425 \quad(80)$ \\
\hline Afternoon PEF $l \cdot \mathrm{min}^{-1}$ & $630(78)^{*}$ & 594 (91) & $576(101)$ & $456(68)^{*}$ & $441 \quad(86)$ & $438 \quad(74)$ \\
\hline Amplitude $\%$ mean $^{\dagger}$ & $2.94(1.88)^{*}$ & $3.25(1.93)$ & 4.18 (1.94) & $3.76(2.07)^{* *}$ & $3.65(2.07)$ & $4.30(2.29)$ \\
\hline Day-to-day PEF & $0.11(1.21)$ & $-0.03 \quad(1.30)$ & $0.16(1.37)$ & $0.23(1.49)$ & $-0.12(2.18)$ & $-0.01(1.74)$ \\
\hline
\end{tabular}

Data are presented as mean (SD). Differences tested with ANCOVA or Kruskall-Wallis ANOVA, adjusted for age and height in morning and afternoon PEF and adjusted for age in amplitude \% mean and in day-to-day variation; + ${ }^{+}$data on smoking habit of three males were missing. $\quad$ : amplitude $\%$ mean and standard deviation are expressed in geometric values (transformed back after calculations on $\log _{10}$-transformed data); *: significant difference in mean values in smoking groups, $\mathrm{p}<0.05$; **: borderline significant difference in mean values in smoking groups, $0.05<\mathrm{p}<0.10$; PEF: peak expiratory flow; ANCOVA: analysis of covariance; ANOVA: analysis of variance.

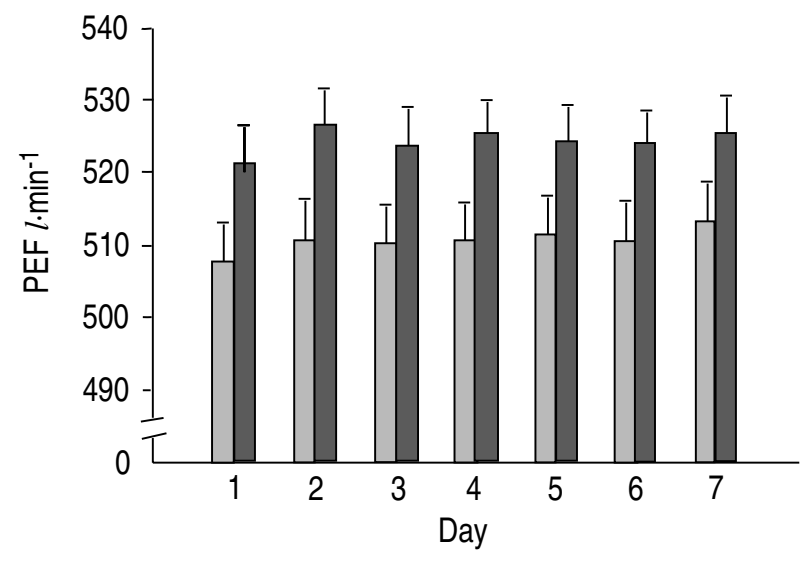

Fig. 1. - Mean morning peak expiratory flow (PEF $\left.l \cdot \mathrm{min}^{-1}\right)(\square)$ and afternoon PEF ( $\square$ ) with SEM in the total study population ( $\mathrm{n}=$ 511) by day. phenomenon of a training-effect $[4,17]$. Therefore, the data from day 1 were excluded from the analyses. After this exclusion, nine subjects had less than the obliged 5 days. Their data were not analysed. Thus, data of 511 subjects, 265 males and 246 females, aged 2070 yrs were used for analyses. Population characteristics are shown in table 1 .

\section{Gender differences}

Mean morning PEF and mean afternoon PEF in males and females were normally distributed (table 2). Morning and afternoon PEF were associated with sex, age and height. Younger males had a higher morning and afternoon PEF than older males, independent of height, the same being true in females (table 3). Age and height

Table 2. - Characteristics of the distribution of morning peak expiratory flow (PEF), afternoon PEF, amplitude \% mean and day-to-day variation in morning PEF, in the total population and by gender

\begin{tabular}{|c|c|c|c|c|c|c|}
\hline & Mean & Median & SD & Kurtosis & Skewness & $\begin{array}{c}\mathrm{K}-\mathrm{S}^{*} \\
\text { p-value }\end{array}$ \\
\hline \multicolumn{7}{|l|}{ Total } \\
\hline Morning PEF $l \cdot \mathrm{min}^{-1}$ & 510 & 502 & 113 & -0.312 & -0.079 & 0.377 \\
\hline Afternoon PEF $l \cdot \mathrm{min}^{-1}$ & 524 & 517 & 112 & -0.249 & -0.066 & 0.441 \\
\hline Amplitude $\%$ mean $^{\dagger}$ & 3.66 & 3.73 & 2.03 & 4.508 & 0.826 & 0.933 \\
\hline Day-to-day PEF & 0.08 & 0.00 & 1.53 & 18.082 & -0.989 & $<0.001$ \\
\hline \multicolumn{7}{|l|}{ Males } \\
\hline Morning PEF $l \cdot \mathrm{min}^{-1}$ & 582 & 592 & 96 & 0.636 & -0.730 & 0.108 \\
\hline Afternoon PEF $l \cdot \mathrm{min}^{-1}$ & 597 & 608 & 94 & 0.815 & -0.751 & 0.228 \\
\hline Amplitude $\%$ mean $^{\dagger}$ & 3.48 & 3.50 & 1.95 & 1.361 & 0.542 & 0.971 \\
\hline Day-to-day PEF & 0.08 & 0.00 & 1.30 & 7.205 & 0.349 & $<0.001$ \\
\hline \multicolumn{7}{|l|}{ Females } \\
\hline Morning PEF $l \cdot \mathrm{min}^{-1}$ & 436 & 443 & 78 & 0.786 & 0.713 & 0.160 \\
\hline Afternoon PEF $l \cdot \mathrm{min}^{-1}$ & 448 & 451 & 75 & 1.355 & -0.741 & 0.066 \\
\hline Amplitude $\%$ mean $^{\dagger}$ & 3.86 & 3.97 & 2.13 & 7.709 & 1.009 & 0.907 \\
\hline Day-to-day PEF & 0.08 & 0.00 & 1.74 & 19.727 & -1.541 & $<0.001$ \\
\hline
\end{tabular}

*: Kolmogorov-Smirnov (K-S) test for normality of distribution; ${ }^{\dagger}$ : tested on the log-transformed distribution. Mean amplitude $\%$ mean, median, standard deviation, kurtosis and skewness are transformed back after calculations on $\log _{10}$-transformed data. 
Table 3. - Regression coefficients and standard errors of multiple regression analyses with morning peak expiratory flow (PEF), afternoon PEF and amplitude \% meant as dependent variable and mean centred age, mean centred height and pack-years as independent variables, stratified by gender

\begin{tabular}{|c|c|c|c|c|c|c|c|}
\hline \multirow[t]{3}{*}{ Variables } & \multicolumn{4}{|c|}{ Males $(n=265)$} & \multicolumn{3}{|c|}{ Females $(n=246)$} \\
\hline & \multirow{2}{*}{$\begin{array}{l}\text { Morning PEF } \\
\text { B } \quad(\mathrm{SE})\end{array}$} & \multicolumn{2}{|c|}{ Afternoon PEF } & \multirow{2}{*}{$\underset{\mathrm{B}}{\operatorname{Amp}} \% \underset{\text { mean }}{\mathrm{SE})}$} & \multirow{2}{*}{ Morning PEF } & \multirow{2}{*}{$\begin{array}{l}\text { Afternoon PEF } \\
\begin{array}{ll}\text { B } & (\mathrm{SE})\end{array}\end{array}$} & \multirow{2}{*}{$\begin{array}{c}\text { Amp } \% \text { mean } \\
\mathrm{B}\end{array}$} \\
\hline & & B & & & & & \\
\hline Constant & $600.1(7.16)^{* * *}$ & 613.2 & $(6.97)^{* * *}$ & $3.29(1.060)^{* * * *}$ & $447.4(4.86)^{* * *}$ & $460.5 \quad(4.66)^{* * *}$ & $3.60 \quad(1.054)^{* * * *}$ \\
\hline M.C. Age ${ }^{+}$ & $-1.27(0.417)^{* *}$ & -1.32 & $(0.406)^{* *}$ & $0.001(0.0015)$ & $-1.84(0.309)^{* * * *}$ & $-1.60(0.296)^{* * *}$ & $0.006(0.0015)^{* * *}$ \\
\hline M.C. Height ${ }^{++}$ & $420.1(76.49)^{* * *}$ & 417.0 & $(74.55)^{* * *}$ & $-0.351(0.2710)$ & $226.7(69.07)^{* * * *}$ & $221.7(66.22)^{* * * *}$ & $-0.219(0.3289)$ \\
\hline Pack-years & $-1.17(0.341)^{* * *}$ & -1.07 & $(0.331)^{* *}$ & $0.002(0.0012)$ & $-1.60(0.315)^{* * *}$ & $-1.71(0.302)^{* * * *}$ & $0.004(0.0015)^{* *}$ \\
\hline RSD & 80.4 & 78.3 & & 0.28 & 64.6 & 61.9 & 0.31 \\
\hline
\end{tabular}

$\dagger$ : analyses have been performed on geometric values of amplitude $\%$ mean (transformed back after calculations on $\log _{10}-$ transformed data); B: regression coefficient; SE: standard error. RSD: residual standard deviation. ${ }^{* * *}: \mathrm{p}<0.001 ;{ }^{* *}: \mathrm{p}<0.01 ;{ }^{*}: \mathrm{p}<0.05$. ${ }^{+}$: mean centred age males $=($age -46.7$) ;$ mean centred age females $=($ age -44.5$) ;{ }^{++}$: mean centred height males $=($height -1.79$)$; mean centred height females $=($ height -1.66$)$.

adjusted mean morning PEFs and afternoon PEFs were significantly lower in females than males. This difference remained after adjustment for smoking. A larger number of pack-years is associated with a lower mean morning PEF both for males and females (table 3). In accordance, male current smokers had the lowest mean morning PEF (557 (101) $\left.l \cdot \mathrm{min}^{-1}\right)$, male ex-smokers an intermediate mean morning PEF (580 (94) $\left.l \cdot \mathrm{min}^{-1}\right)$ and males who never smoked the highest mean morning PEF (620 (78) $l \cdot \mathrm{min}^{-1} ; \mathrm{p}<0.001$; adjusted for age and height) (table 1). The same pattern was present in mean morning PEF of females (respectively, 425 (80), 432 (84) and $443(74) l \cdot \mathrm{min}^{-1} ; \mathrm{p}<0.05$; adjusted for age and height), and in the mean afternoon PEF of both sexes. The relationships between age, PEF according to smoking habit are visualized in regression plots in figure $2 \mathrm{a}$ and $\mathrm{b}$.

The mean afternoon PEF (524 (112) $\left.l \cdot \mathrm{min}^{-1}\right)$ was significantly higher than the mean morning PEF for the total population (510 (113) $\left.l \cdot \mathrm{min}^{-1}\right)$ (paired t-test, $\left.\mathrm{p}<0.001\right)$. The absolute difference between afternoon and morning $\mathrm{PEF}$ was associated with age in females $(\mathrm{B}=0.22, \mathrm{p}<0.01$; adjusted for height), but not in males. The absolute

a)

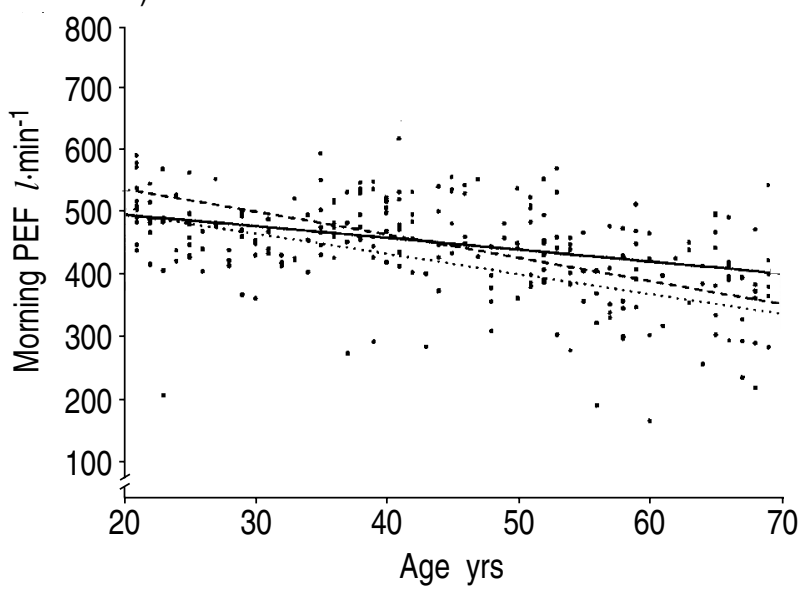

difference was significantly greater in males than in females (ANCOVA, $\mathrm{p}<0.001$; adjusted for age, height and pack-years). This gender difference disappeared after adjustment for morning PEF (including an interaction term of morning PEF and gender) $(\mathrm{p}>0.05)$.

\section{Within-day variation (Amplitude \% mean)}

As the amplitude \% mean was not normally distributed but skewed to the right (KS-test, $\mathrm{p}<.0 .001$ ) (fig. 3), testing was performed on $\log _{10}$-transformed data. The mean values of the amplitude \% mean in the current population were lower than those described in previous studies $[14,17,18]$. Females had a significantly higher amplitude \% mean than males (ANCOVA; $\mathrm{p}=0.022$; adjusted for age, height and pack-years). The gender difference in amplitude \% mean remained significant $(\mathrm{p}=0.0153)$ after adjustment for an interaction term of age and gender (mean centred age * sex).

There was an association between the magnitude of the amplitude $\%$ mean and age, with older people having

$$
\text { b) }
$$

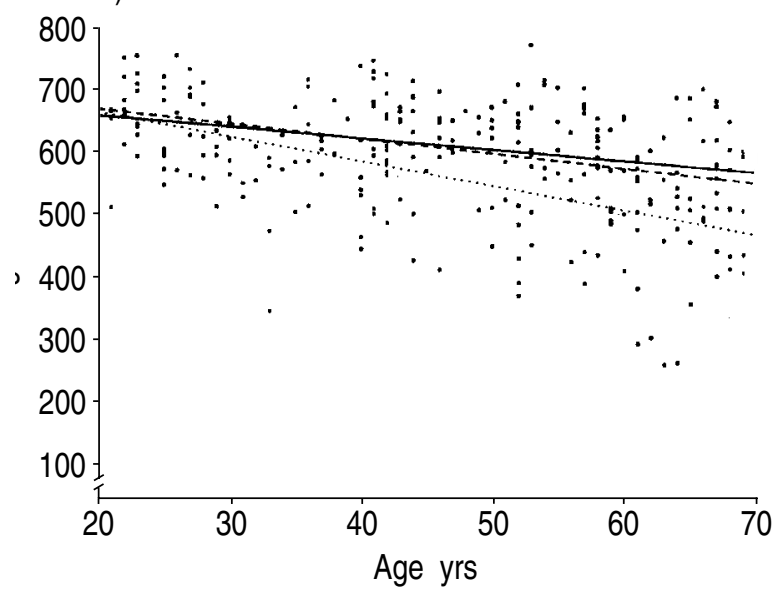

Fig. 2. - a) Morning peak expiratory flow (PEF) in $l \cdot \mathrm{min}^{-1}$ by age in females $(\mathrm{n}=246)$, according to smoking habit; b) Morning PEF in $l \cdot \mathrm{min}{ }^{-1}$ by age in males $(n=265)$, according to smoking habit. _ plots. 


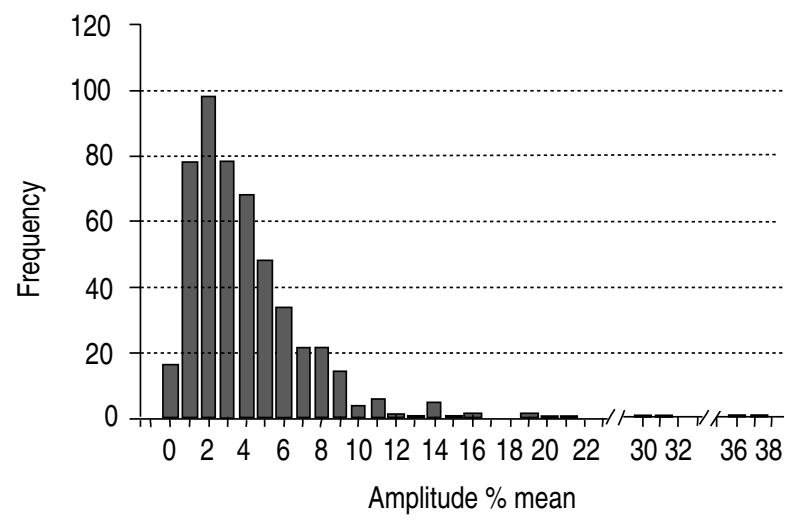

Fig. 3. - Diurnal peak expiratory flow (PEF) variability (amplitude $\%$ mean) of the total study population $(n=511)$.

higher amplitudes than younger people, both in females and in males (table 3 ). There was an association between height and amplitude \% mean. This association was related with the age effect, and did not reach significance after adjustment for age (table 3 ). In males the highest amplitude \% mean was found in current smokers, followed by, respectively, ex-smokers and neversmokers (ANCOVA, $\mathrm{p}<0.005$; adjusted for age) (table 1). The pattern was less consistent in females. Female current smokers had the highest amplitude \% mean and female ex-smokers the lowest (ANCOVA, 0.05< $\mathrm{p}<0.10$; adjusted for age). The amplitude $\%$ mean increased with the amount of pack-years (table 3 ).

Exclusion of those subjects $(n=29 ; 5.7 \%)$ who reported to have (had) doctor diagnosed asthma or used bronchodilators $(\mathrm{n}=23 ; 4.5 \%)$, did not change the dependencies of the amplitude \% mean on age, height and pack-years, shown in table 3.

\section{Day-to-day variation of morning PEF}

The distribution of day-to-day variation of morning PEF was skewed to the right (table 2). Log-transformation (performed on absolute, log-transformed or reciprocal values) did not normalize the distribution. There was no significant difference in day-to-day variation in females and males (Mann Whitney U-test, $\mathrm{p}=0.775$ ). Day-to-day variation was related to age, with on average the highest variation in the oldest age group $(\mathrm{r}=0.159 ; \mathrm{p}<0.001)$. Day-to-day variation was not related to former or current smoking habits, the amount of pack-years (table 1), or to height.

\section{Discussion}

The current analyses show that, in a random population sample, absolute PEF values are normally distributed. Absolute PEF values are lower on the first measurement day than on the other days. Mean morning PEFs are lower than mean afternoon PEFs. These results confirm the findings reported by other investigators $(8,13-15,17)$. PEF variability, expressed as amplitude \% mean, has a normal distribution after logtransformation, whereas day-to-day variation of morning $\mathrm{PEF}$ is not normally distributed and this remains so after log-transformation. Males have higher mean values of PEF than females, independent of age, height and smoking habits. Absolute PEF values are lower in older age groups than in younger ones, both for males and females. Amplitude \% mean is higher in older age groups than in younger ones, and this is independent of the absolute PEF values. Smoking is associated with lower mean values of absolute PEF at all ages, and therefore with greater amplitude $\%$ mean. Females have a greater amplitude \% mean than males. The analyses show that this is largely due to a different association of $P E F$ and age in females than in males. The difference between morning and afternoon PEF is higher at older ages in females, but not in males. This unexpected observation remains unexplained.

Independent of smoking habits, the amplitude \% mean in older groups tends to be higher than in the younger ones. This trend is significant both for females and males. This result is in accordance with results presented by Neukirch et al. [17], who studied 117 blue-collar workers and HigGins et al. [18] who studied PEF variability in a random sample of adults. We found that this greater PEF variability at older ages is due not only to lower mean PEF values, but also the result of greater absolute differences between afternoon and morning PEF. The same divergency has been described in a study population measuring PEFs at two hourly intervals during waking hours [18].

The mean values of the amplitude $\%$ mean as observed in these analyses are lower than has been described by other investigators. This may be the result of various factors. One may be the fact that we have measured PEF twice daily, whereas others have measured PEF more than twice a day $[8,14,17]$. Both in large scale community-based studies and in general health practice, one has to strike a balance between feasibility - and consequently compliance - and reliability. Patients may be better motivated to perform several measurements. In occupational studies of subjects with similar activities during the day (or in school children), repeated measurements at fixed time-points seem easier to achieve. The heterogeneity of the current community based sample of both males and females aged 20-70 yrs may present problems in achieving reliable measurements at 4 or 5 time-points during the day. Futhermore, standard diaries provided by the manufacturer of the peak flow meters also use two daily measurements. For these reasons we preferred to ask for not more than two daily measurements.

Another possible explanation is that the absolute PEF is supposed to be close to the minimum in the early morning at rising, and to the maximum at the end of the day. However, this may not be true for all subjects, minimalizing the difference between morning and afternoon PEF. Subjects may also rise at different times in the morning. Thus, the moment at which minimum and maximum PEF values occur may differ between subjects, and the set time of the day to measure the PEF (at 
rising and between 5 and 6 p.m.) for the whole study population may be inappropriate for some individuals. Indeed, in our study, some subjects had very similar morning and afternoon PEF values. However, as such, a limited variability of PEF is biologically plausible. Some subjects may have no or very little lability of the bronchial tree, resulting in small diurnal PEF variability. If challenge testing with histamine or methacholine is used to assess bronchial lability, there are also some subjects who do not react to challenge with any decrease of their forced expiratory volume in one second $\left(\mathrm{FEV}_{1}\right)$, even if high doses of histamine or methacholine are applied [7].

General practitioners who use PEF variability assessed by two daily measurements to monitor treatment effects in patients in their home situation, should be aware that amplitude \% mean scores may be slightly lower than those usually mentioned in the literature on the basis of clinical investigations with more than two measurements per day. This will explicitly be the case if they do not exclude any measurements.

To our knowledge, this is the first study with data on mean day-to-day variation in morning PEF in a random population sample. BRAND et al. [9] reported mean day-to-day variation of 0.18 in a group of patients with respiratory diseases. In the current study, there is little consistent day-to-day variation in the morning PEF values. Median day-to-day morning PEF values are zero (table 2). This indicates that, in a random population sample, most subjects seem to have a stable morning PEF, and variation in PEF occurs within-the-day rather than between days. Further studies are needed to assess the sensitivity of day-to-day variability as a parameter of respiratory function and symptoms, compared to mere absolute PEF or the amplitude \% mean.

In these cross-sectional data we found differences in the magnitude of morning PEF over several age groups in relation to smoking. For all ages, the mean morning $\mathrm{PEF}$ of lifetime nonsmokers is higher than the mean morning PEF of ex-smokers and current smokers. Although they are on average older than the current smokers, we found both male and female ex-smokers to have higher morning PEFs than current smokers. CoOK et al. [20] found, in subjects aged over 65 yrs, similar differences in relation to smoking habits. Data presented by GREGG and NunN [21] showed no significant reduction in PEF in male or female ex-smokers of fewer than 20 cigarettes $\cdot$ day $^{-1}$. Unlike the current analyses, Gregg and Nunn did not account for the number of pack-years in ex-smokers. We found that the amount of pack-years is significantly associated with lower PEF values and higher amplitude \% mean.

The method of keeping diaries with PEF values at home has certain limitations. We gave no instructions to perform PEF measurements if a subject woke up in the night. Because of this, some severe dipping may have been missed. We assume, however, that we were nevertheless able to detect such episodes because they result in lower morning PEF compared to normal. Furthermore, the investigator can never be sure that the same subject performs the measurements, nor that all values are scored without error and are the result of appropriate performance. This misclassification may bias the estimates towards no effect. Nevertheless, keeping PEF diaries at home is generally considered as a feasible method of collecting PEF and PEF variability data in large population samples at reasonable costs and effort. In the current study, with $90 \%$ of the subjects returning an adequate PEF recording form, a satisfactory response rate was achieved in all age ranges. There is only a small training effect in this population including older subjects.

We conclude that PEF and PEF variability have a normal or log-normal distribution, permitting standard statistical procedures. Females do have both a lower absolute PEF and higher diurnal variability than males, independent of age, height and smoking habits. Further studies are needed to assess the association of bronchial lability, expressed as PEF variability, with respiratory symptoms or other outcome variables. In these studies age, gender and smoking habits should be taken into account.

Acknowledgements: These results are from a local analysis of data collected for the European Community Respiratory Health Survey. Any final international comparison may use a different form of analysis. Glaxo Pharmaceuticals kindly provided the peak flow meters.

\section{References}

1. Hargreave FE, Ryan G, Thomson NC, et al. Bronchial responsiveness to histamine or methacholine in asthma: measurement and clinical significance. J Allergy Clin Immunol 1981; 68: 347-355.

2. Rijcken B, Schouten JP, Weiss ST, Speizer FE, Van der Lende R. The relationship of nonspecific bronchial responsiveness to respiratory symptoms in a random population sample. Am Rev Respir Dis 1987; 136: 6268.

3. Higgins BG, Britton JR, Chinn S, Cooper S, Burney PGJ, Tattersfield AE. Comparison of bronchial reactivity and peak expiratory flow variability measurements for epidemiologic studies. Am Rev Respir Dis 1992; 145: 588-593.

4. Higgins BG, Britton JR, Chinn S, Jones TD, Burney PGJ, Tattersfield AE. Relationship of methacholine $\mathrm{PD}_{20}$ and peak flow variability measurements to respiratory symptoms in a community population. Am Rev Respir Dis 1988; 137: A249.

5. Cockcroft DW, Berscheid BA, Murdock KY. Unimodal distribution of bronchial responsiveness to inhaled histamine in a random human population. Chest 1983, 83: 751-754.

6. Yan K, Salome CM, Woolcock AJ. Prevalence and nature of bronchial hyperresponsiveness in subjects with chronic obstructive disease. Am Rev Respir Dis 1985; 132: 25-29.

7. Rijcken B, Schouten JP, Weiss ST, Meinesz AF, De Vries K, Van der Lende R. The distribution of bronchial responsiveness to histamine in symptomatic and asymptomatic subjects; a population-based analysis of various indices of responsiveness. Am Rev Respir Dis 1989; 140: 615-623.

8. Quackenboss JJ, Lebowitz MD, Krzyzanowski M. The 
normal range of diurnal changes in peak expiratory flow rates. Am Rev Respir Dis 1991; 143: 323-330.

9. Brand PLP, Postma DS, Kerstjens HAM, Köeter GH, and the Dutch CNSLD Study Group. Relationship of airways hyperresponsiveness to respiratory symptoms and diurnal peak flow variation in patients with obstructive lung disease. Am Rev Respir Dis 1991: 143: 916-921.

10. Ryan G, Latimer KM, Dolovich J, Hargreave FE. Bronchial responsiveness to histamine, relationship to diurnal variation of peak flow rate, improvement after bronchodilatator, and airway calibre. Thorax 1982; 37: 423-429.

11. Ramsdale EH, Morris MM, Hargreave FE. Interpretation of the variability of peak flow rates in chronic bronchitis. Thorax 1986; 41: 771-776.

12. Trigg CJ, Bennett JB, Tooley M, Sibbald B, D'Souza MF, Davies RJ. A general practice based survey of bronchial hyperresponsiveness and its relation to symptoms, sex, age, atopy, and smoking. Thorax 1990; 45: 866-872.

13. Hetzel MR, Clark TJH. Comparison of normal and asthmatic circadian rhythms in peak expiratory flow rate. Thorax 1980; 35: 732-738.
14. Higgins BG, Britton JR, Chinn S, et al. The distribution of peak expiratory flow variability in a population sample. Am Rev Respir Dis 1989; 140: 1368-1372.

15. Hetzel MR. The pulmonary clock. Thorax 1981; 36: 481486.

16. Connolly CK. Diurnal rhythms in airway obstruction. Br J Dis Chest 1979; 73: 357-366.

17. Neukirch F, Liard R, Segala C, Korobaeff M, Henry C, Cooreman J. Peak expiratory flow variability and bronchial responsiveness to methacholine. Am Rev Respir Dis 1992; 146: 71-75.

18. Higgins BG, Briton JR, Chinn S, Lai KK, Burney PGJ, Tattersfield AE. Factors affecting peak expiratory flow variability and bronchial reactivity in a random population sample. Thorax 1993; 48: 899-905.

19. Information leaflet mini-Wright peak flow meter. Clement Clarke International Ltd, Martins Press, London.

20. Cook NR, Evans DA, Scherr PA, et al. Peak expiratory flow rate in an elderly population. Am J Epidemiol 1989; 130: 66-78.

21. Gregg I, Nunn AJ. Peak expiratory flow in symptomless elderly smokers and ex-smokers. $\mathrm{Br}$ Med J 1989; 298: 1071-1072. 